\title{
A comparative study of psychiatric comorbidity and quality of life between tension-type headache patients and healthy controls
}

\author{
Arpit Jaiswal ${ }^{1}$, Ekaansh Sharma ${ }^{2}$, Chinar Sharma ${ }^{3}$, Simran Sharma ${ }^{4}, K_{\text {Kumar Utkarsh }}^{5}$, \\ Ramjan Ali ${ }^{6}$ \\ ${ }^{1}$ Assistant Professor, ${ }^{2,3,4}$ Postgraduate Resident, ${ }^{5}$ Senior Resident, Department of Psychiatry, Rohilkhand Medical \\ College and Hospital, ${ }^{6}$ Associate Professor, Department of Psychiatry, Varun Arjun Medical College and Rohilkhand \\ Hospital, Bareilly, Uttar Pradesh, India
}

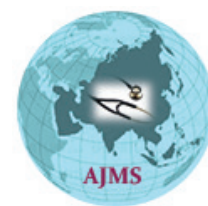

A B S TR A C T

Background: Headache is a health disorder that affects a large proportion of the world population, resulting in a huge economic burden. Nearly half the world's population has a history of current headache disorder. Its prevalence is reported to vary over a wide range from $1.3 \%$ to $65 \%$ in men and $2.7 \%$ to $86 \%$ in women. It is responsible for 7.2 million years of life lived with disability. The present study was planned to study the prevalence and clinical impact of psychiatric comorbidity and quality of life among patients with tension-type headache (TTH) in a North Indian population. Aims and Objectives: To assess the psychiatric comorbidity and quality of life among the patients of Tension type Headache and compare them with healthy controls. Materials and Methods: Patients presenting with complaints of headache and healthy individuals without complaints of headache were included in the study. A total of 100 patients were studied that were presenting in tertiary care hospital. Patients were subjected to a semi-structured interview, diagnosis made by ICHD-3 for TTH, and psychiatric comorbidity was detected by Mini-International Neuropsychiatric Interview applied to both patients and controls. Results: Psychiatric morbidity was diagnosed in $90 \%$ of cases and only $9 \%$ of controls. Among cases with psychiatric morbidity, generalized anxiety disorder $(28 \%)$ was the most common, followed by major depressive disorder (MDD) (27\%), panic disorder (12\%), social phobia (11\%), agoraphobia (6\%), alcohol dependence $(4 \%)$, and substance dependence (2\%), respectively. On the other hand, among controls, $7 \%$ had MDD and $2 \%$ had alcohol dependence. Statistically, a significant difference was found between the two groups $(\mathrm{P}<0.001)$. The quality of life of TTH patients with psychiatric comorbidity was significantly lower as compared to that of TTH patients without psychiatric morbidity. Conclusion: The findings of the study showed a much higher prevalence of psychiatric comorbidity among TTH patients as compared to matched healthy controls. The quality of life of TTH patients was highly impaired, presence of psychiatric comorbidity made the quality of life of affected patients even worse.

\section{Access this article online}

Website:

http://nepjol.info/index.php/AJMS DOI: 10.3126/ajms.v13i2.40853

E-ISSN: 2091-0576

P-ISSN: 2467-9100

Copyright (c) 2022 Asian Journal of Medical Sciences

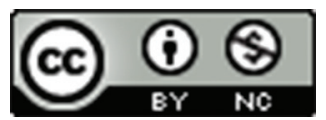

This work is licensed under a Creative Commons Attribution-NonCommercial 4.0 International License.

Key words: Psychiatric comorbidity; Quality of life; Tension-type headache

\section{INTRODUCTION}

Headache is a neurological condition experienced by almost all persons during their lifetime. Most of the time it is ignored as a benign condition not having any serious consequences; however, it may sometimes be associated with a life-threatening condition. ${ }^{1}$ The most commonly occurring and benign types of headaches are primary headaches. The term tension-type headache (TTH) describes the cluster of conditions earlier known as "tension headache, muscle contraction headache, stress headache, and psychomyogenic headache, respectively." However, in the year 1988, International Headache Classification designated all these entities into a single entity 
that is now known as TTH. ${ }^{2}$ TTH is the $3^{\text {rd }}$ most common type of disorder in the world and the most common type of headache among all the headaches. ${ }^{3}$ There is a high prevalence of psychiatric morbidities such as depression, post-traumatic stress disorder, generalized anxiety disorder (GAD), and suicidal ideation among migraine and TTH patients. ${ }^{4}$ TTH has also been known to affect the sleep pattern and cause insomnia. ${ }^{5}$ Although there are a number of studies addressing this issue, most of them are from abroad and there is a lack of studies from India exploring the inter-relationship between TTH, quality of life, and psychiatric comorbidity. Hence, the present study was planned to find out the prevalence and clinical impact of psychiatric comorbidity and quality of life among patients with TTH in a North Indian population.

\section{Aims and objectives}

To assess the psychiatric comorbidity and quality of life among the patients of Tension type Headache and compare them with healthy controls.

\section{MATERIALS AND METHODS}

This was a hospital-based analytical cross-sectional study. This study was approved by the Ethical Committee of the institute before the commencement of the study and carried out in the outpatient department of psychiatry in a tertiary care hospital. Written and informed consents from the patient or caregiver, as appropriate were taken. The duration of the study was 1 year. The total sample size was 100 patients each of headache patients and control group. Patients presenting with complaints of headache were taken as cases and healthy individuals accompanying the patients without complaints of headache and any known psychiatric illness were taken as controls. Diagnosis of any major physical illness (diabetes, hypertension, asthma, or any other chronic illness) in the patient expected to influence the outcome of the study and subject with the already existing psychiatric disorder before the onset of TTH in the patient were excluded from the study. Whereas either the healthy relatives accompanying the patients with TTH or the staff members of the hospital who are willing to give written and informed consent to participate in the study with the age range of 18-65 years of either sex were included as healthy controls.

Diagnoses according to ICHD-3 guidelines were made which include:

At least 10 episodes of headache occurring on more than 1 day/month on average ( $>12$ days/year) and fulfilling criteria b-d. Lasting from 30 minutes to 7 days. At least two of the following four characteristics should be present: (a) bilateral location, (b) pressing or tightening (non-pulsating) quality, (c) mild or moderate intensity, (d) not aggravated by routine physical activity such as walking or climbing stairs. Both of the following criteria should also be present (a) no nausea or vomiting, (b) no more than one of photophobia or phonophobia. $^{6}$

For psychiatric comorbidity, the Mini-International Neuropsychiatric Interview is used, which is a short structured diagnostic interview, developed jointly by psychiatrists and clinicians in the United States and Europe, for DSM-IV and ICD-10 psychiatric disorders. ${ }^{7}$

For quality of life, "The World Health Organization Quality of Life (WHOQOL) is applied which is a quality of life assessment developed by the WHOQOL group in an attempt to develop a quality of life assessment that would be applicable cross-culturally." This scale contains certain domains which measures quality of life in different aspects of dimension of health which are as follows:

Domain 1 - Physical health

Domain 2 - Psychological health

Domain 3 - Social relationships

Domain 4 - Environmental health

G1 and G2 are the general questions about quality of life and health. ${ }^{8}$

The patient's sociodemographic details and clinical profile were recorded in a semi-structured pro forma designed, especially for the study.

For statistical analysis, the data were collected and analyzed using Statistical Package for the Social Sciences version 21.0. Chi-square test and independent samples " $\mathrm{t}$ "test were used to compare the data. $\mathrm{P}<0.05$ was considered to be statistically significant.

\section{RESULTS}

Out of 100 patients with TTH, 90 had some psychiatric comorbidity, on the other hand, out of 100 controls, only nine had psychiatric comorbidity.

Sociodemographic data, as depicted in Table 1, show the mean age of cases and controls as $36.66 \pm 12.88$ and $39.72 \pm 12.97$, respectively. The majority of cases $(73 \%)$, as well as controls (65\%), were male. Mean years of education were $7.94 \pm 6.08$ in the case group and $6.57 \pm 5.74$ in the control group. The duration of illness in cases ranged from 6 to 36 months with a mean duration of $13.91 \pm 5.87$ months.

The prevalence of psychiatric comorbidity among the cases and controls is shown in Table 2. Among cases with 


\begin{tabular}{|c|c|c|c|c|}
\hline \multirow[t]{2}{*}{$\begin{array}{l}\text { Sociodemographic } \\
\text { data }\end{array}$} & \multirow{2}{*}{$\begin{array}{c}\begin{array}{c}\text { Case } \\
(n=100)\end{array} \\
n(\%)\end{array}$} & \multirow{2}{*}{$\begin{array}{c}\begin{array}{c}\text { Control } \\
(n=100)\end{array} \\
n(\%)\end{array}$} & \multirow[t]{2}{*}{$\begin{array}{c}\chi^{2} \\
\text { value }\end{array}$} & \multirow[t]{2}{*}{$\begin{array}{l}\text { "P" } \\
\text { value }\end{array}$} \\
\hline & & & & \\
\hline \multicolumn{5}{|l|}{ Age group } \\
\hline 20-29 years & $30(30 \%)$ & $28(28 \%)$ & 1.654 & 0.096 \\
\hline $30-39$ years & $38(38 \%)$ & $25(25 \%)$ & & \\
\hline $40-49$ years & $9(9 \%)$ & $17(17 \%)$ & & \\
\hline $50-59$ years & $16(16 \%)$ & $24(24 \%)$ & & \\
\hline$\geq 60$ years & $7(7 \%)$ & $6(6 \%)$ & & \\
\hline \multicolumn{5}{|l|}{ Sex } \\
\hline Male & $73(73 \%)$ & $65(65 \%)$ & 1.396 & 0.221 \\
\hline Female & $27(27 \%)$ & $35(35 \%)$ & & \\
\hline \multicolumn{5}{|l|}{ Educational status } \\
\hline Illiterate & $35(35 \%)$ & $41(41 \%)$ & 1.638 & 0.103 \\
\hline Primary & 0 & 0 & & \\
\hline Middle & 0 & 0 & & \\
\hline High School & $22(22 \%)$ & $30(30 \%)$ & & \\
\hline Intermediate & $22(22 \%)$ & $19(19 \%)$ & & \\
\hline Graduate & $21(21 \%)$ & $10(10 \%)$ & & \\
\hline \multicolumn{5}{|l|}{ Occupation } \\
\hline Unemployed & $36(36 \%)$ & $46(46 \%)$ & 2.740 & 0.254 \\
\hline $\begin{array}{l}\text { Unskilled } \\
\text { employment }\end{array}$ & $46(46 \%)$ & $35(35 \%)$ & & \\
\hline Skilled employment & $18(18 \%)$ & $19(19 \%)$ & & \\
\hline \multicolumn{5}{|l|}{ SES } \\
\hline Upper class & $2(2 \%)$ & $2(2 \%)$ & 0.218 & 0.994 \\
\hline Upper middle class & $26(26 \%)$ & $24(24 \%)$ & & \\
\hline Lower middle class & $35(35 \%)$ & $34(34 \%)$ & & \\
\hline Upper lower class & $35(35 \%)$ & $38(38 \%)$ & & \\
\hline Lower class & $2(2 \%)$ & $2(2 \%)$ & & \\
\hline
\end{tabular}

\begin{tabular}{|c|c|c|}
\hline \multirow[t]{2}{*}{ Psychiatric morbidity } & $\begin{array}{c}\text { Case } \\
(n=100)\end{array}$ & $\begin{array}{c}\text { Control } \\
(n=100) \text { GAD }\end{array}$ \\
\hline & $\mathrm{n}(\%)$ & $\mathrm{n}(\%)$ \\
\hline Major depressive disorder & $27(27 \%)$ & $7(7 \%)$ \\
\hline Panic disorder & $12(12 \%)$ & 0 \\
\hline Agoraphobia & $6(6 \%)$ & 0 \\
\hline Social phobia & $11(11 \%)$ & 0 \\
\hline Alcohol dependence & $4(4 \%)$ & $2(2 \%)$ \\
\hline Substance dependence & $2(2 \%)$ & 0 \\
\hline $\begin{array}{l}\text { Generalized anxiety } \\
\text { disorder }\end{array}$ & $28(28 \%)$ & 0 \\
\hline No & $10(10 \%)$ & $91(91 \%)$ \\
\hline
\end{tabular}

psychiatric morbidity, GAD $(28 \%)$ was the most common, followed by major depressive disorder (MDD) (27\%), panic disorder $(12 \%)$, social phobia (11\%), agoraphobia $(6 \%)$, alcohol dependence (4\%), and substance dependence $(2 \%)$, respectively. On the other hand, controls comprise MDD (7\%) and alcohol dependence (2\%). Statistically, significant differences have been found between the two groups $(\mathrm{P}<0.001)$ as seen in Fig 1.

Qualities of life among cases with and without psychiatric morbidity (Table 3) show that mean scores for G1, G2,

\begin{tabular}{|c|c|c|c|c|c|c|}
\hline \multirow[t]{2}{*}{ Domain } & \multicolumn{2}{|c|}{$\begin{array}{c}\text { With } \\
\text { psychiatric } \\
\text { morbidity } \\
(n=90)\end{array}$} & \multicolumn{2}{|c|}{$\begin{array}{c}\text { Without } \\
\text { psychiatric } \\
\text { morbidity } \\
(n=10)\end{array}$} & \multicolumn{2}{|c|}{$\begin{array}{c}\text { Statistical } \\
\text { significance }\end{array}$} \\
\hline & Mean & SD & Mean & SD & "t'" & "P" \\
\hline G1 & 3.01 & 0.81 & 4.00 & 0.00 & 3.824 & $<0.001$ \\
\hline G2 & 2.47 & 0.50 & 3.20 & 0.42 & 4.446 & $<0.001$ \\
\hline Domain 1 & 38.42 & 9.42 & 54.80 & 2.53 & 5.452 & $<0.001$ \\
\hline Domain 2 & 40.10 & 11.79 & 50.00 & 16.59 & 2.413 & 0.018 \\
\hline Domain 3 & 34.42 & 14.65 & 75.00 & 0.00 & 8.722 & $<0.001$ \\
\hline Domain 4 & 43.40 & 6.93 & 59.00 & 5.54 & 6.872 & $<0.001$ \\
\hline
\end{tabular}

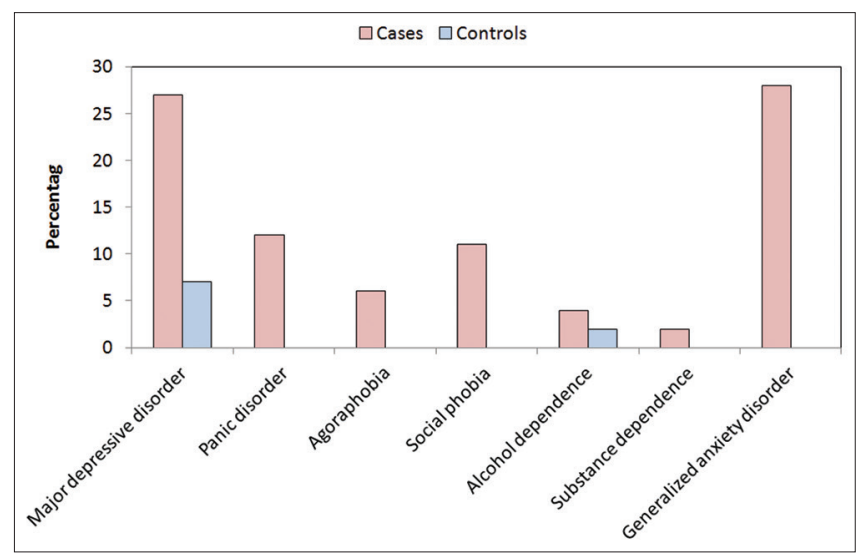

Figure 1: Distribution of the study population according to psychiatric morbidity (MINI). MINI: Mini-International Neuropsychiatric Interview

Domain 1 (physical), Domain 2 (psychological), Domain 3 (social), and Domain 4 (environmental) were $3.01 \pm 0.81$, $2.47 \pm 0.50,38.42 \pm 9.42,40.10 \pm 11.79,34.42 \pm 14.65$, and $43.40 \pm 6.93$, respectively, as compared to another group $4.00 \pm 0$, $3.20 \pm 0.42,54.80 \pm 2.53,50.00 \pm 16.59,75.00 \pm 0.00$, and $59.00 \pm 5.54$, respectively, thus showing a significant difference between the two groups $(\mathrm{P}<0.05)$ for both $\mathrm{G} 1$ and $\mathrm{G} 2$ sections as well as all the four domains which is represented in Fig 2 .

\section{DISCUSSION}

Headache is a condition that not only affects the ability of an individual to work but also affects the family life and leisure time of an individual. ${ }^{9}$ Headache is also related to sleep disturbances which affect the normal routine and sleep pattern has a detrimental effect on the psychosocial well-being of an individual resulting in decay in quality of life. The relationship between headache and psychiatric morbidity is bidirectional at the one end of which is headache that results in psychiatric morbidity ${ }^{10}$ on the other end of it is a psychiatric illness as the primary illness resulting into headache as the secondary illness. ${ }^{11,12}$

In the present study, psychiatric comorbidity was found to be statistically significant in TTH patients. GAD was 


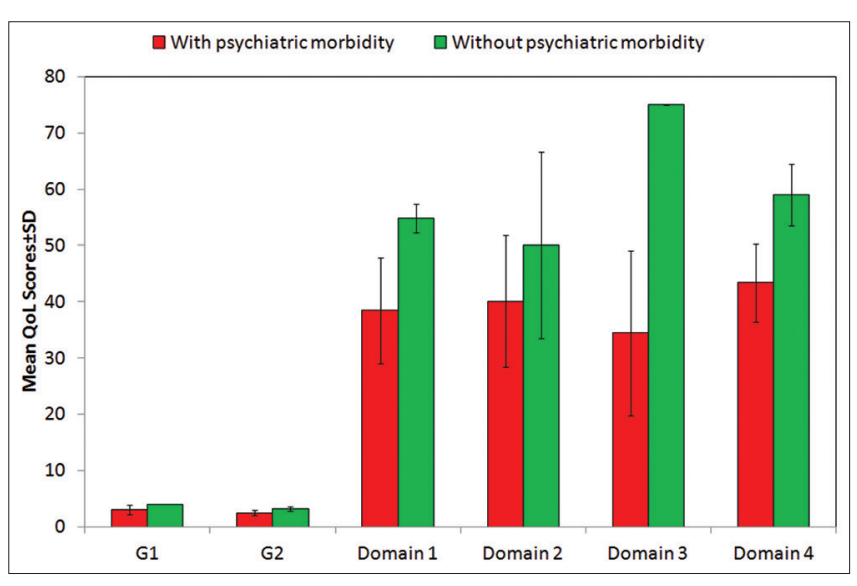

Figure 2: Comparison of quality of life assessment scores between cases with and without psychiatric morbidity

found to be most prevalent among the psychiatric disorders followed by depressive disorders. This finding correlates with the study conducted by Shoib et al., ${ }^{13}$ and Martins et al., ${ }^{14}$ which found the prevalence of psychiatric morbidity in TTH patients as $48.9 \%$ and $60.8 \%$, respectively, among which GAD was the most common followed by depression.

In concordance with the study conducted by Beghi et al., ${ }^{15}$ in which they included migraine and TTH patients and found that the prevalence of psychiatric morbidity, that is, depressive symptoms, anxiety, panic disorder, and obsessive-compulsive disorder is $12.8 \%, 67 \%, 19.3 \%, 5.5 \%$, and $1.1 \%$ among TTH patients. In another study, Bera et al., ${ }^{16}$ reported the prevalence of psychiatric morbidity to be $60 \%$ in TTH patients as compared to $22.5 \%$ in controls, thus showing a significantly higher prevalence of psychiatric morbidity in TTH patients as compared to controls.

This finding in our study can be explained by the chronic nature of the headache and also because in our culture, psychiatric symptoms are neglected and not considered to be a part of an illness and add up to the severity of the disorder. The presence of anxiety among the cases of headache may be due to the apprehensions related to TTH and the severity of symptoms in early cases.

The findings of our study show that TTH is associated with a decay in quality of life which further deteriorates with the presence of psychiatric morbidity. The quality of life of patients of T'TH has been reported to be affected adversely in cases compared with controls by Bera et al. ${ }^{16}$ in which quality of life was affected in all the four domains which are in concordance with our study. Martins et al., ${ }^{14}$ concluded that the presence of psychiatric comorbidity in headache patients significantly lowers quality of life which is also observed in our study. Van Suijlekom et al., ${ }^{17}$ reported Mean QoL scores for "physical functioning, social functioning, role limitations - physical, role limitations - emotional, mental health, vitality, bodily pain and general," respectively, in TTH patients and found them to be significantly lower as compared to that in controls.

\section{Limitations of the study}

There was no information regarding medication history and burden of loss of occupational opportunities which could have helped to explain the greater burden of psychiatric morbidity and quality of life decline in TTH patients. Moreover, information related to the level of family support could also have helped to understand the protective effect of same to cope with psychological burden of disease. Further studies with inclusion of more dimensions to the problem and a comparative assessment concerning different types of headache are recommended.

\section{CONCLUSION}

TTH is clinically and pathophysiologically heterogeneous. There have been many studies conducted for TTH in regard to involvement with psychological distress and poor quality of life. Increased frequency of TTH is associated with higher rates of psychiatric disorders, with anxiety disorders appearing to be more prevalent than depression. The presence of psychiatric comorbidity in TTH patients negatively impacts the quality of life. The prevalence of TTH and the psychological functioning assessment is understudied till date. Therefore, a detailed mental status examination and careful clinical evaluation are required in patients with TTH for a better treatment outcome which will, in turn, improve their quality of life.

\section{ACKNOWLEDGMENT}

I would like to say thanks to Dr. Arpit Jaiswal, Dr. Ekaansh Sharma, Dr. Chinar Sharma, Dr. Kumar Utkarsh and Dr. Simran Sharma for their expertise and assistance throughout all aspects of our study and for their help in writing the manuscript.

\section{REFERENCES}

1. Stovner LJ, Hagen K, Jensen R, Katsarava Z, Lipton R, Scher A, et al. The global burden of headache: A documentation of headache prevalence and disability worldwide. Cephalalgia. 2007;27(3):193-210.

https://doi.org/10.1111/j.1468-2982.2007.01288.x

2. Headache classification committee of the international headache society the international classification of headache disorders. Cephalalgia. 2018;38(1):1-211.

https://doi.org/10.1177/0333102417738202

3. Ashina M. Neurobiology of chronic tension-type headache. 
Cephalalgia. 2004;24(3):161-172.

https://doi.org/10.1111/j.1468-2982.2003.00644.x

4. Chai NC, Rosnberg JD and Peterlin BL. The epidemiology and comorbidities of migraine and tension-type headache. Tech Reg Anesth Pain Manag. 2012;16(1):4-13.

https://doi.org/10.1053/j.trap.2012.11.001

5. Rains JC, Davis RE and Smitherman TA. Tension-type headache and sleep. Curr Neurol Neurosci Rep. 2015;15(2):520.

https://doi.org/10.1007/s11910-014-0520-2

6. Headache Classification Committee of the International Headache Society. The international classification of headache disorders, $3^{\text {rd }}$ edition (beta version). Cephalalgia. 2013;33(9):629-808. https://doi.org/10.1177/0333102413485658

7. Sheehan DV, Lecrubier Y, Sheehan KH, Amorim P, Janavs J, Weiller E, et al. The Mini-International Neuropsychiatric Interview (M.I.N.I.): The development and validation of a structured diagnostic psychiatric interview for DSM-IV and ICD-10. J Clin Psychiatry. 1998;59(Suppl 20):22-33; quiz 34-57.

8. The World Health Organization quality of life assessment (WHOQOL): Development and general psychometric properties 1998;46(12):1569-1585.

https://doi.org/10.1016/s0277-9536(98)00009-4

9. Linde $M$ and Dahlof $C$. Attitudes and burden of disease among self-considered migraineurs-a nation-wide population-based survey in Sweden. Cephalalgia. 2004;24(6):455-465.

https://doi.org/10.1111/j.1468-2982.2004.00703.x

10. Holroyd KA, Stensland M, Lipchik GL, Hill KR, O'Donnell FS and Cordingley G. Psychosocial correlates and impact of chronic tension-type headaches. Headache. 2000;40(1):3-16.

https://doi.org/10.1046/j.1526-4610.2000.00001.x
11. Smitherman TA and Baskin SM. Headache secondary to psychiatric disorders. Curr Pain Headache Rep. 2008;12(4):305-310.

https://doi.org/10.1007/s11916-008-0051-0

12. Registrar General, Census of India 2011. Census of India Website: Office of the Registrar General \& Census Commissioner, India (censusindia.gov.in)

13. Shoib S, Mushtaq R, Ahmad SR and Arif T. Recognizing risk of psychiatric comorbidity in headache: Looking for symptoms of anxiety and depression in headache: A study from general hospital in Kashmir (India). J Depress Anxiety. 2014;S1:6. https://doi.org/10.4172/2167-1044.S1-006

14. Martins V, Temotio J and Murta I. Psychiatric Comorbidities Associated with Headaches: The experience of the liaison consultation. Acta Med Port. 2015;28(1):44-50. https://doi.org/10.20344/amp.5541

15. Beghi E, Bussone G, D’Amico D, Cortelli P, Cevoli S, Camillo G, et al. Headache, anxiety and depressive disorders: The HADAS study. J Headache Pain. 2010;11(2):141-150. https://doi.org/10.1007/s10194-010-0187-2

16. Bera SC, Khandelwal SK, Sood M and Goyal V. A comparative study of psychiatric comorbidity, quality of life and disability in patients with migraine and tension type headache. Neurol India. 2014;62(5):516-520. https://doi.org/10.4103/0028-3886.144445

17. van Suijlekom HA, Lamé I, Stomp-van den Berg SG, Kessels $A G$ and Weber WE. Quality of life of patients with cervicogenic headache: A comparison with control subjects and patients with migraine or tension-type headache. Headache. 2003;43(10):1034-1041.

https://doi.org/10.1046/j.1526-4610.2003.03204.x

\section{Authors Contribution:}

ES, CS, and SS - Concept and design of the study, prepared first draft of manuscript; AJ and KU- Interpreted the results, reviewed the literature, and manuscript preparation; and RA - Concept, coordination, statistical analysis and interpretation, preparation of manuscript, and revision of the manuscript.

\section{Work attributed to:}

Rohilkhand Medical College and Hospital, Bareilly - 243 006, Uttar Pradesh, India.

Orcid ID:

Dr. Arpit Jaiswal - (1) https://orcid.org/0000-0002-4146-072X

Dr. Ekaansh Sharma - (D https://orcid.org/0000-0002-0974-2719

Dr. Chinar Sharma - (D) https://orcid.org/0000-0002-3868-6859

Dr. Simran Sharma - (1) https://orcid.org/0000-0002-6674-3662

Dr. Ramjan Ali - (1) https://orcid.org/0000-0002-2144-8360

Source of Support: None, Conflict of Interest: None. 